\title{
RESEARCH ON THE OPTIMIZATION OF THE ANALYSIS METHOD OF ECOLOGICAL ENVIRONMENT EMISSION DATA
}

\author{
ChEn, G. B. ${ }^{1}-$ LIU, J. M. ${ }^{2,3,4 *}$ \\ ${ }^{1}$ Chongqing Key Laboratory of Spatial Data Mining and Big Data Integration for Ecological \\ and Environment, Rongzhi College of Chongqing Technology and Business University \\ Chongqing 401320, P. R. China
}

${ }^{2}$ College of Mathematics and Computer Science, Quanzhou Normal University Quanzhou 362000, Fujian, P. R. China

${ }^{3}$ Fujian Provincial Key Laboratory of Data Intensive Computing Quanzhou 362000, Fujian, P. R. China

${ }^{4}$ Fujian Provincial Big Data Research Institute of Intelligent Manufacturing Quanzhou 362000, Fujian, P. R. China

\author{
The first two departments contributed equally to this work and are considered co-first \\ departments. \\ *Corresponding author \\ e-mail:liujmcqu19995@163.com \\ (Received $8^{\text {th }}$ Mar 2019; accepted 21 ${ }^{\text {st }}$ May 2019)
}

\begin{abstract}
In order to reduce the emission of ecological environment and the pollution of ecological environments and improve the sustainable development of ecological economy, so an improved model of the wavelet (War) based on the improved gravity optimization algorithm (IGSA) is proposed (IGSAWar). The method uses an improved gravitational algorithm to optimize the wavelet, establish an optimization model, and predict the different NOx emissions of coal-fired boilers. Firstly, the grid algorithm is used to initialize the population, and the particle is updated based on the fitness value adaptive decrements inertia weight. Numerical simulation results verify the effectiveness and superiority of the proposed algorithm (López-Hernández, 2018). Then the IGSA is used to optimize the selected hyper-parameters to improve the prediction accuracy and generalization ability of the model; the wavelet model optimizes the noisy emission data to reduce the impact of noise on the system. Finally, taking the discharge of $330 \mathrm{MW}$ coal-fired boiler in a thermal power plant as the research object, the NOx soft measurement model of IGSA-War is established. The simulation results show that the optimization model has high prediction accuracy and generalization ability, and can effectively measure NOx emissions.
\end{abstract}

Keywords: nitrogen oxide, gravitational algorithm, wavelet model, IGSA-War, numerical optimization

\section{Introduction}

With the rapid development of chinese economy, ecological deterioration has become an important factor constraining economic development. emissions are in a deteriorating state (Tan and Xia, 2014; Niu et al., 2016; Khanchoul et al., 2018). In order to effectively predict and rationally manage ecological NOx, [something has to be done] thereby reducing NOx emissions and establishing a predictive model of NOx (Lv et al., 2017; Hossain et al., 2019). Artificial intelligence technology is a typical representative of neural network and support vector machine due to its good ability to deal with non-linearity (Li et al., 2003; Zhang et al., 2015; Franco et al., 2018), which can better solve the problem of NOx modeling. In the NOx model prediction process, 
the support vector machine (Rashedi et al., 2009; Niu et al., 2014; Nouaim et al., 2019), has received more and more attention in the modeling of NOx emissions due to the lack of over-fitting and generalization of neural networks. The NOx emission prediction problem has complex non-linearity, mufti-dimensional mufti-mode, and few data samples, and needs to solve the problem of structural risk minimization. How to obtain the optimal super-parameter is the key to the accuracy of NOx emission model (Yazdani et al., 2014; Gouthamkumar et al., 2015; Azeem et al., 2018). In fact, the wavelet analysis hyper-parameter adjustment process is also a parameter optimization process. The combustion optimization based on wavelet and optimization technology is an effective way to reduce NOx emissions of boilers (Liu and Niu, 2015; Sharjeel et al., 2019).

\section{Materials and methods}

\section{Basic Principles of GSA Algorithm}

In the GSA, the position $\left\{X_{i}\right\}, i=1,2, \cdots, N$ of each particle is a feasible solution to the optimization problem, (Pascual-Córdova, 2018) and $\mathrm{N}$ is the size of the population, where the position of the $\mathrm{i}$-th particle is $X_{i}=\left(x_{i}^{1}, x_{i}^{2}, \cdots, x_{i}^{s}\right)$, and $\mathrm{s}$ is the dimension of the optimization problem. The GSA is based on the fitness value and uses the Eq.1 to update the quality of the particle:

$$
\left\{\begin{array}{l}
m_{i}(t)=\frac{f i t_{i}(t)-\operatorname{worst}(t)}{\operatorname{best}(t)-\operatorname{worst}(t)} \\
M_{i}(t)=\frac{m_{i}(t)}{\sum_{j=1}^{N} m_{j}(t)}
\end{array}\right.
$$

where $f_{i t}(t)$ is the fitness value of the $\mathrm{i}$-th particle; for minimization:

$\operatorname{best}(t)=\max _{j \in\{1, \cdots N\}} f i t_{j}(t)$, worst $(t)=\min _{j \in\{1, \cdots N\}} f i t_{j}(t)$.

At a specific time $t$, the gravitational force acting between particle $\mathrm{j}$ and particle $\mathrm{i}$ is defined as:

$$
F_{i j}^{d}(t)=G(t) \frac{M_{i}(t) \times M_{j}(t)}{R_{i j}(t)+\varepsilon}\left(x_{j}^{d}(t)-x_{i}^{d}(t)\right)
$$

where $M_{i}$ and $M_{j}$ are the masses of the mass points; $\varepsilon$ is a smaller constant; $R_{i j}(t)$ is the distance between the mass points; $G(t)$ is the gravitational constant. Then the resultant force acting on the $\mathrm{d}$-th dimension of the $\mathrm{i}$-th particle is:

$$
F_{i}^{d}(t)=\sum_{j=1, j \neq i}^{N} \operatorname{rank}_{j} F_{i j}^{d}(t)
$$

where $\operatorname{rank}_{j}$ is a random number in $[0,1]$.

Through the law of motion, (Espinoza, 2017) the acceleration of the mass point $i$ in the dimension at time $\mathrm{t}$ : 


$$
a_{i}^{d}(t)=\frac{F_{i}^{d}(t)}{M_{i}(t)}
$$

In the GSA algorithm, the speed and position of the particle are updated as follows:

$$
\left\{\begin{array}{c}
v_{i}^{k}(t+1)=\operatorname{rank}_{i} \times v_{i}^{k}(t)+a_{i}^{k}(t) \\
x_{i}^{k}(t+1)=x_{i}^{k}(t)+v_{i}^{k}(t+1)
\end{array}\right.
$$

where $\operatorname{rank}_{j}$ is a random number in $[0,1]$.

\section{Improved GSA algorithm}

Although the GSA algorithm has better optimization performance, when dealing with some complex optimization problems, GSA still has the disadvantages of premature convergence and easy to fall into the local optimal solution. Therefore, its ability to seek still needs further improvement.

\section{Grid-based algorithm for initializing populations}

The first step in the GSA algorithm is to initialize the population. (Jaimes, 2017). A good initial population that covers the entire solution space can help improve the speed of evolution and improve the quality of the solution. If the local solution space containing the global optimal solution is not in the initial group space, and the position update algorithm of the particle cannot extend the coverage space to the region where the global optimal solution is located within a finite number of evolution, premature convergence is not possible. Avoid, it can be seen that the distribution of the initial population individuals directly affects the global convergence performance of the algorithm. The initial population of the original GSA algorithm is randomly distributed, and its coverage space has a large uncertainty. In this paper, the grid algorithm is used to initialize the position group of the particle, so that the initial individual is evenly distributed in the sea, and its expression is as a Eq.6:

$$
x_{i}^{k}=\min (k)+\frac{\max (k)-\min (k)}{n-1} i
$$

where: $x_{i}^{k}$ represents the k-th component of the $\mathrm{i}$-th $(\mathrm{i}=1,2, \ldots, \mathrm{N})$ motion mass points; $\max (k)$, $\min (k)$ are the upper and lower bounds of the $\mathrm{k}$-th component.

It is not difficult to find that the population is initialized by gridding, so that the ergodicity of the population can be improved under the premise of ensuring the randomness of the initial variables, so that the algorithm traverses all possible states, (Dager, 2017) which is beneficial to overcome the general random initialization of the population and the optimization algorithm search. Limitations.

\section{Adaptive weight based on fitness value}

In order to further improve the optimization performance of the GSA algorithm and avoid the premature phenomenon appearing in the optimization of complex highdimensional multi-mode functions, (Olivares et al., 2017) the researchers have carried out a lot of research work and proposed a linear decreasing weight strategy. Although it 
is beneficial to improve the optimization performance to a certain extent, ( $\mathrm{Li}$ and $\mathrm{Zhao}$, 2017; Kumar, 2018) the algorithm does not take into account the fitness value of the optimization problem, and it may reduce the optimization performance when dealing with some complex nonlinear optimization problems. Therefore, based on the linear decreasing inertia weight, this paper proposes an adaptive decreasing inertia weight position update strategy based on the fitness:

$$
\left\{\begin{array}{l}
t_{i}=\left(t_{\text {start }}-t_{\text {end }}\right) \frac{\text { maxier }-i}{\text { maxiter }}+t_{\text {end }} \\
\Phi_{\text {fit }}=\frac{2}{1+{ }^{\text {fit }}} \text { - } \\
w_{i}=\Phi_{\text {fit }}-t_{i}
\end{array}\right.
$$

where $t_{\text {start }}$ and $t_{\text {end }}$ are the initial value and the final value, respectively, and $0<t_{\text {end }}<t_{\text {start }}<1$, maxier and $i$ are the maximum number of iterations of the GSA and the current algebra, respectively, $t_{i}$ is the linearly decreasing inertia weight, and $\Phi_{\text {fit }}$ is the fitness value factor whose value fit changes, $w_{i}$ is an adapt decreasing inertia weight.

Substituting Eq.7 into equation Eq.5 to obtain the position update formula of the particle:

$$
x_{i}^{k}(t+1)=w_{i} * x_{i}^{k}(t)+v_{i}^{k}(t+1)
$$

$w_{i}$ determines the domain range generated by $x_{i}^{k}$. This range will decrease correspondingly as the search approaches the optimal solution, which will help the GSA to better use prior knowledge to improve the optimization ability of the algorithm.

\section{IGSA optimization steps}

Figure 1 shows a flow chart of the improved IGSA algorithm. The specific steps are as follows:

1) Initialization parameters: maximum number of iterations $\max =1000$, population number $\mathrm{N}=50$;

2) The grid algorithm initializes the population;

3) Calculating the fitness value of the population point;

4) update data $\mathrm{G}(\mathrm{t})$, best(t), worst(t)and $\mathrm{M}_{i}, i=1,2, \ldots, N$;

5) Update the resultant force of the particles in all directions according to Eq.3;

6) Calculate the velocity of the particle according to Eq.5;

7) Update the position of the mass point according to Eq.7 and Eq.8, $t_{\text {start }}$ and $t_{\text {end }}$ are set to 1 and 0 , respectively;

8) Repeat steps (3) (7) until the stop condition is met.

\section{IGSA performance verification}

Complex function optimization has become a research hotspot in the field of optimization algorithms. This paper selects 13 standard functions to evaluate the optimization performance of IGSA. f1 f7 are single-mode functions with only one extreme point. They are mainly used to investigate the execution ability of the algorithm (Chen et al., 2017) and test the optimization precision of the algorithm; f8 f13 is a 
multi-modal function, which has a large number of local best advantages, and is a wellrecognized function that is well-recognized in the optimization field. Most optimization algorithms often seek to optimize them. Will fall into the local best, they are mainly used to test whether the algorithm has the ability to avoid premature and search for the global optimal solution, except for the minimum value of f8 is $-418.9829 \times \mathrm{n}$ ( $\mathrm{n}$ is the dimension of the solution), the other 12 functions. The minimum values are all zero. Reference (Liu et al., 2015; Rajput et al., 2019) describes in detail the range of values for the standard function solution, and points out that the original GSA is superior to PSO, RGA and CFO. This paper will conduct a comparative study of IGSA and the original GSA algorithm (Kang et al., 2017, 2018; Zulkapli et al., 2018).

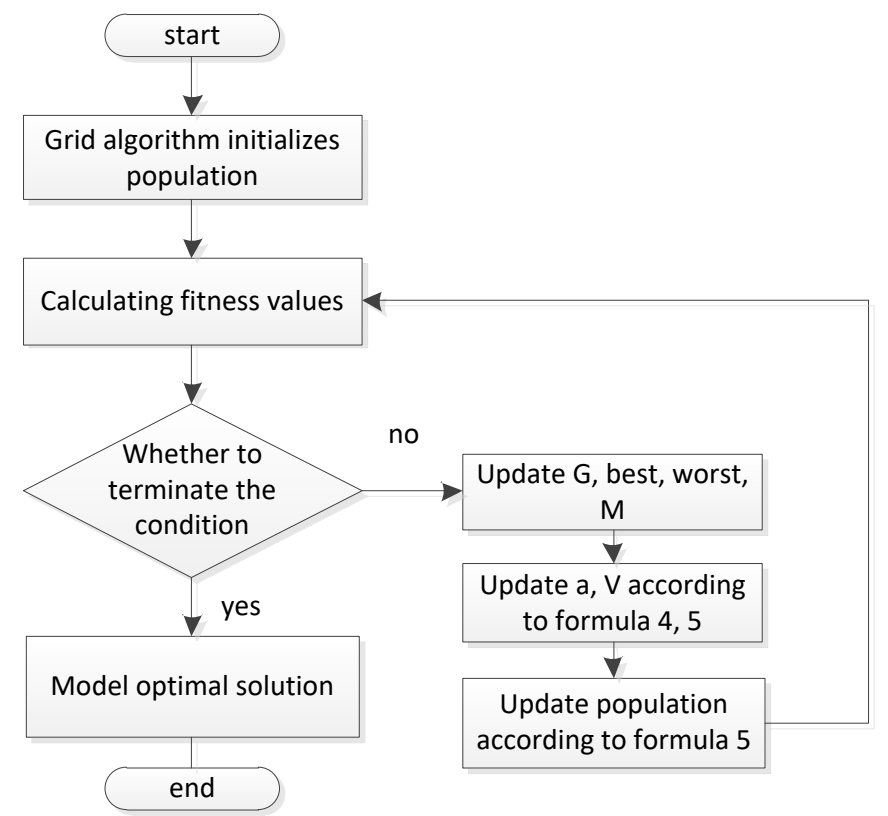

Figure 1. The program flowchart of IGSA

In order to effectively reduce the impact of random interference, each runs independently 30 times. Table 1 gives the statistics data of the average convergence iteration number (CI), average optimal fitness value (Mean) and standard deviation (SD) of the function in 30-dimensional and 50-dimensional cases.

Observe and analyze the optimization results of the 13 standard test functions given in Table 1. It is found that for the single-mode function, except for $\mathrm{f6}$, in the three algorithms, (Zhang and Khalique, 2018) whether the function is 30 or 50, the optimization effect of IGSA is the best. And the advantages are obvious; for multimodal functions, except for f12, the optimization effect of IGSA is the best. Therefore, the superior solution of IGSA has the highest accuracy compared to GSA. At the same time, (Pang et al., 2016) it is found that when $n=50$, the optimization precision of IGSA is basically close to the accuracy of $n=30$, which indicates to some extent that the optimization effect of IGSA has not been weakened as the complexity of the problem increases. In comparison, with the increase of the dimension of GSA, most of the optimization effects show a downward trend (Table 1).

The standard deviation reflects the robustness of the algorithm, and the average function convergence times C.I. reflects the computational convergence speed of the 
algorithm. It can be seen from Table 1 that ABC and GSA can't always solve the 13 standard functions accurately. It can be clearly observed that the optimization performance of IGSA is more accurate than that of GSA, and the ability to jump out of local extremum is stronger. In terms of optimization speed, the CI index of IGSA is small; from the standard deviation, it can be seen that the GSA is unstable in solving the single-peak and multi-peak continuous functions. Relatively speaking, IGSA is the most stable.

Table 1. The comparison of performance of 2 algorithms for 13 standard functions with $\operatorname{dim}=30,50$

\begin{tabular}{|c|c|c|c|c|c|c|c|}
\hline \multirow{2}{*}{ Fun } & \multirow{2}{*}{ Dim } & \multicolumn{3}{|c|}{ GSA } & \multicolumn{3}{|c|}{ IGSA } \\
\hline & & C.I. & Mean & SD & C.I. & Mean & SD \\
\hline \multirow[b]{2}{*}{$f_{1}$} & 30 & 1000 & $1.9735 \times 10^{-17}$ & $3.1255 \times 10^{-17}$ & 956 & 0 & 0 \\
\hline & 50 & 1000 & $6.8852 \times 10^{-17}$ & $3.8521 \times 10^{-17}$ & 956 & 0 & 0 \\
\hline \multirow{2}{*}{$f_{2}$} & 30 & 1000 & $2.3617 \times 10^{-8}$ & $2.4311 \times 10^{-8}$ & 1000 & $4.5447 \times 10^{-240}$ & 0 \\
\hline & 50 & 1000 & $1.8237 \times 10^{-6}$ & $3.2107 \times 10^{-6}$ & 1000 & $8.2777 \times 10^{-240}$ & 0 \\
\hline \multirow{2}{*}{$f_{3}$} & 30 & 1000 & 245.2465 & 124.1475 & 956 & 0 & 0 \\
\hline & 50 & 1000 & $1.0389 \times 10^{3}$ & $8.0389 \times 10^{2}$ & 941 & 0 & 0 \\
\hline \multirow{2}{*}{$f_{4}$} & 30 & 1000 & $3.4666 \times 10^{-9}$ & $4.6413 \times 10^{-9}$ & 1000 & $7.2535 \times 10^{-241}$ & 0 \\
\hline & 50 & 1000 & 3.6869 & 1.3257 & 1000 & $7.1133 \times 10^{-241}$ & 0 \\
\hline \multirow{2}{*}{$f_{5}$} & 30 & 1000 & 26.2523 & 3.2792 & 123 & 6.5915 & 0.0335 \\
\hline & 50 & 1000 & 51.2594 & 1.4218 & 128 & 38.7057 & 0.0319 \\
\hline \multirow[b]{2}{*}{$f_{6}$} & 30 & 1000 & $1.8800 \times 10^{-17}$ & $0.9811 \times 10^{-17}$ & 105 & 3.1384 & 0.3688 \\
\hline & 50 & 1000 & $6.6512 \times 10^{-17}$ & $4.1126 \times 10^{-17}$ & 111 & 10.1299 & 0.6813 \\
\hline \multirow[b]{2}{*}{$f_{7}$} & 30 & 1000 & 0.0264 & $2.2791 \times 10^{-3}$ & 746 & $1.2265 \times 10^{-5}$ & $3.5151 \times 10^{-5}$ \\
\hline & 50 & 1000 & 0.1206 & 0.0925 & 414 & $4.2318 \times 10^{-5}$ & $2.7627 \times 10^{-5}$ \\
\hline \multirow[b]{2}{*}{$f_{8}$} & 30 & 1000 & $-2.7251 \times 10^{3}$ & 72.2457 & 265 & -12763.23 & 35.3552 \\
\hline & 50 & 1000 & $-3.733 \times 10^{3}$ & 93.6284 & 273 & -20814.63 & 44.8538 \\
\hline \multirow{2}{*}{$f_{9}$} & 30 & 1000 & 17.0801 & 6.0467 & 385 & 0 & 0 \\
\hline & 50 & 1000 & 36.9129 & 3.6118 & 387 & 0 & 0 \\
\hline \multirow{2}{*}{$f_{10}$} & 30 & 1000 & $3.4686 \times 10^{-9}$ & $2.3746 \times 10^{-9}$ & 741 & $8.8818 \times 10^{-16}$ & 0 \\
\hline & 50 & 1000 & $4.9160 \times 10^{-9}$ & $4.2701 \times 10^{-9}$ & 736 & $8.8818 \times 10^{-16}$ & 0 \\
\hline \multirow{2}{*}{$f_{11}$} & 30 & 1000 & 3.9239 & 0.1092 & 361 & 0 & 0 \\
\hline & 50 & 1000 & 18.2615 & 0.4593 & 357 & 0 & 0 \\
\hline \multirow{2}{*}{$f_{12}$} & 30 & 1000 & 0.0374 & 0.0102 & 103 & 0.5733 & 0.2041 \\
\hline & 50 & 1000 & 0.4460 & 0.0043 & 105 & 0.7983 & 0.0548 \\
\hline \multirow{2}{*}{$f_{13}$} & 30 & 1000 & 1.6696 & 0.9618 & 100 & 0.0055 & 0.0557 \\
\hline & 50 & 1000 & 0.2697 & 0.0612 & 90 & 0.0038 & 0.0871 \\
\hline
\end{tabular}

\section{Ecological emission prediction models}

\section{Wavelet prediction model}

Wavelet analysis is based on the Fourier transform. However, the problem is that the transformation discards the time information, and the transformation result cannot accurately analyze the occurrence of traffic and related indicators. (Zhang et al., 2017) The general wavelet transform refers to the inner product of the signal $x(t)$ to be analyzed after the basic wavelet function $\psi(\mathrm{t})$ is translated by $\mathrm{m}$ and at different scales n.

$$
W T_{\mathrm{x}}(n, m)=\frac{1}{\sqrt{a}} x(t) \psi^{*}\left(\frac{t-m}{n}\right) d t
$$


The equivalent time domain expression is:

$$
=\int x(t) \psi_{n, m}^{*}(t) d t
$$

$$
W T_{\mathbf{x}}(n, m)=\frac{1}{\sqrt{a}} \int x(\omega) \psi^{*}\left(\frac{\omega-m}{n}\right) e^{j \omega} d t \quad a>0
$$

\section{Prediction model based on IGSA-War combination}

For the predicted emissions to meet the predicted effect, the specific test steps are given here:

When $\mathrm{t}$ is used, the actual NOx output of the boiler is $\mathrm{O}$, and the actual discharge amount $W_{t}$ is St. In order to reduce the suddenness of the emissions and improve the prediction accuracy, the delay $D_{t}$ and the length $L_{t}$ of the emissions are mainly used here. Analysis, ie $S_{t}=\left[D_{t}, L_{t}\right]$. In order to effectively deal with the possible occurrence of emission congestion, reasonable queue management is implemented by analyzing the current and past time emissions status to obtain the next-time emission status $Z_{t+1}$. The following combines the emission state prediction algorithm:

Step 1: Initialize the ecological emission model and its related parameters at the starting time $\mathrm{t}=0$;

Step 2: At time t, the actual emission amount $W_{t}$ at node $\mathrm{O}$ is obtained, and its state vector $S_{t}$ is obtained, and it is judged according to the IGSA model whether the service is distributed therefrom, if the measurement is satisfied, the process jumps to step 3 , otherwise, the process proceeds to step 7;

Step 3: solves the delay $D_{\mathrm{t}+1}^{\prime}$ and the length $L_{\mathrm{t}+1}^{\prime}$ of the service flow at time $\mathrm{t}+1$;

$$
\left\{\begin{array}{c}
D_{\mathrm{t}+1}^{\prime}=1-(1-\lambda) \sum_{n=0}^{\infty} \Omega_{m+n+1}((n+1) b-t) \\
L_{\mathrm{t}+1}^{\prime}=(1-\lambda) \sum_{n=0}^{\infty} \Omega_{k+n}(n+1) b
\end{array}\right.
$$

where $\square$ is the discharge load size, b is the buffer size, and $\Omega_{k+n}$ is the distribution function of the actual emissions.

Step 4: For the fractal and burst characteristics of the actual traffic flow, a wavelet transform is introduced to process the traffic flow. According to the wavelet transform shown in Eq.11, the state of the service flow $Y_{t}$ is determined by the Harr wavelet base (time delay $D_{t}$ and queue length $L_{t}$ ) is decomposed to obtain the wavelet coefficient $\mathrm{d}_{\mathrm{j}}(\mathrm{k})$ and the scale factor $\mathrm{a}_{\mathrm{j}}(\mathrm{k})$ :

$$
\left\{\begin{array}{l}
\sqrt{2} a_{j}(k)=a_{j+1}(2 k)+a_{j}(2 k+1) \\
\sqrt{2} d_{j}(k)=d_{j+1}(2 k)+d_{j}(2 k+1)
\end{array}\right.
$$

where $\mathrm{j}$ is the wavelet decomposition level;

Step 5: Predict the wavelet coefficients according to the IGSA model, and use the inverse wavelet transform to synthesize the delay $D_{\mathrm{t}+1}^{\prime \prime}(t+1)$ and the length $L_{\mathrm{t}+1}^{n}(t+1)$;

$$
\mu_{t+1}=-\sum_{k=1}^{\xi} \tau_{k} \mu_{t-1}+\sum_{k=0}^{\delta} \rho_{k} \mu_{t-k}
$$


Step 6: According to step (3) and step (5), the time delay and the captain status information of the actual emissions at time $t+1$ are performed here. The following fusion operations reduce the prediction error:

$$
\left\{\begin{array}{l}
D_{t+1}=\phi D_{t+1}^{\prime}+\varphi D_{t+1}^{n g} \\
L_{t+1}=\phi L_{t+1}^{s}+\varphi L_{t+1}^{n z}
\end{array}\right.
$$

wherein, the fusion parameters $\square$ and $\square$ represent the weight distribution of the two prediction results, and can be dynamically adjusted to obtain an optimal result, and $0 \leq \square \leq 1, \quad 0 \leq \square \leq 1, \quad \square+\square=1$;

Step 7: Let $\mathrm{t}=\mathrm{t}+1$, jump to step (1), and repeatedly calculate the actual emission vector at the next moment until the end;

Step 8: The algorithm ends.

\section{Example simulation and analysis}

\section{Data pre-processing evaluation criteria}

There is a nonlinear and strong coupling relationship between the main steam flow and its related parameters. Conventional modeling methods are often difficult to accurately establish a mathematical model of the main steam flow of the turbine. When selecting the unit model parameters, based on the magnitude of the correlation between the main steam flow and the thermal parameters, combined with the selected load, the adjusted stage pressure, a section of extraction steam temperature, a section of extraction pressure and high pressure cylinder exhaust pressure Enter the variable and the main steam flow as the output variable. Since the historical training data involves different quantities (power, wind speed and temperature), the data needs to be normalized. The normalization formula is:

$$
\hat{x}_{i}=\frac{x_{i}-x_{\min }}{x_{\max }-x_{\min }} \quad i=1,2, \mathrm{~m}, N
$$

where $\hat{x}_{i}$ is the normalized value; $x_{\max }=\max \left(x_{i}\right) ; x_{\min }=\max \left(x_{i}\right)$.

For the normalized prediction result $\mathrm{y}^{\wedge \prime}$, the actual prediction value is $\mathrm{y}(\mathrm{x})=\mathrm{y}^{\prime}\left(x_{\max }-x_{\min }\right)+x_{\min }$.

In order to evaluate the prediction effect of IGSA optimized wavelet model, the normalized MAE, MAPE and RMSE were used to evaluate the model prediction performance. The error formula is

$$
\begin{gathered}
\text { MAE }=\frac{1}{N} \sum_{i=1}^{N}\left|y_{i}-y_{p}\right| \\
\operatorname{MAPE}=\frac{1}{N} \sum_{i=1}^{N} \frac{\left|y_{i}-y_{p}\right|}{y_{i}} \div 100 \% \\
\text { RMSE }=\sqrt{\frac{1}{N} \sum_{i=1}^{N}\left(y_{i}-y_{p}\right)^{2}}
\end{gathered}
$$


where $\mathrm{N}, y_{i}, y_{p}$ are the measured, predicted values and the predicted value of the $\mathrm{i}$-th point respectively.

\section{IGSA-War predicts NOx emissions}

The IGSA algorithm was used to optimize the parameters of the wavelet model to predict the NOx concentration of a $330 \mathrm{MW}$ pulverized coal drum boiler. The prediction results were compared with the standard GSA, the improved GSA algorithm (IGSA) and the improved GSA and wavelet combination (IGSA-War) optimization method (Table 2). In the NOx emission multi-case test, specific data including various operating parameters affecting the combustion characteristics of the boiler, such as power generation load, coal feeder speed, and primary air are shown in Table 2.

Table 2. Part of the original data of boiler operation

\begin{tabular}{|c|c|c|c|c|c|c|c|c|c|c|c|c|c|c|c|c|}
\hline \multirow{2}{*}{ working } & \multirow{2}{*}{$\begin{array}{l}\text { load } \\
\text { /MW }\end{array}$} & \multicolumn{4}{|c|}{\begin{tabular}{|c|}
$\begin{array}{c}4 \text { coal feeder speeds } \\
/ \mathrm{r} / \mathrm{m}\end{array}$ \\
\end{tabular}} & \multicolumn{5}{|c|}{ Secondary wind speed $/ \mathrm{m} / \mathrm{s}$} & \multicolumn{3}{|c|}{\begin{tabular}{|c|} 
Burn out wind opening \\
$1 \%$
\end{tabular}} & \multirow{2}{*}{\multicolumn{2}{|c|}{\begin{tabular}{|c|} 
exhaust \\
temperature \\
$1 \%$ \\
\end{tabular}}} & \multirow{2}{*}{$\begin{array}{c}\text { Oxygen } \\
\text { content } \\
/ \%\end{array}$} \\
\hline & & A & B & $\mathrm{C}$ & $\mathrm{D}$ & $\mathrm{AA}$ & $\mathrm{AB}$ & $\mathrm{BC}$ & $\mathrm{CD}$ & $\mathrm{DE}$ & $\begin{array}{l}\text { OFA } \\
\text { up }\end{array}$ & $\begin{array}{l}\text { OFA } \\
\text { down }\end{array}$ & SOFA & & & \\
\hline 1 & & 339 & 340 & 413 & 419 & .1 & 35 & & 3 & 32.9 & 100 & 100 & c & \multicolumn{2}{|c|}{154.6} & 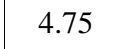 \\
\hline 2 & 320.7 & 328 & 351 & 383 & 86 & .7 & 49 & & 48.3 & & 0 & 0 & 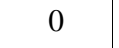 & \multicolumn{2}{|c|}{143.2} & 6.05 \\
\hline 3 & & 340 & 422 & 454 & 301 & 3.7 & 39.7 & 36.0 & 37.8 & 37.5 & 50 & 50 & 100 & \multicolumn{2}{|c|}{150.5} & \\
\hline 1 & 0 & 335 & 339 & 420 & 418 & 34.5 & 38.1 & 36.5 & 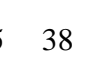 & 34.0 & 0 & 0 & 100 & \multicolumn{2}{|c|}{153} & 4.93 \\
\hline \multirow{2}{*}{ working. } & \multicolumn{8}{|c|}{ Coal quality characteristics $/ \%$} & \multirow{2}{*}{\multicolumn{2}{|c|}{$\begin{array}{c}Q_{a r} / \\
\mathrm{X} 10^{3} \mathrm{~J} / \mathrm{kg} \\
\end{array}$}} & \multicolumn{4}{|c|}{ One wind speed $/ \mathrm{m} / \mathrm{s}$} & \multicolumn{2}{|c|}{$\mathrm{NO}_{\mathrm{x}}$ emission } \\
\hline & $C_{a r}$ & $H_{a r}$ & $a$ & & $C_{a r}$ & $W_{a r}$ & $A_{a r}$ & & & & $\mathrm{I}$ & II & III & IV & & $\mathrm{Ig} / \mathrm{M}$ \\
\hline 1 & 37 & 3.81 & 5 & & 1.20 & 6 & 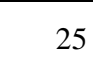 & & & & 27.6 & 29 & 2 & 29.4 & & 85.9 \\
\hline 2 & 62.79 & 3.96 & 0.7 & & 1.25 & 10.5 & 14.5 & & & & 29.5 & 29.8 & 29.4 & 28.3 & & 00.1 \\
\hline 3 & 60.47 & 3.7 & 5.9 & & 1.24 & 8.4 & 19.8 & & & & 29.3 & 27.6 & 28.3 & 28 & & 24.65 \\
\hline 19 & 58.37 & 3.81 & 5. & & 1.21 & 6.4 & 25 & & 20 & & 28.3 & 28.4 & 28.9 & 28.7 & & 27.5 \\
\hline
\end{tabular}

The IGSA is used to optimize the penalty coefficient $\mathrm{C}$ and the kernel function parameter $\sigma^{2}$ in the wavelet, and the optimized wavelet model is used to predict the NOx emissions. Using IGSA to optimize the wavelet model parameters, set the IGSA population size to 50. In the 19 sets of conditions in Table 3, select 3 to 17 sets of data for training optimization modeling, and 1 and 2 groups as prediction data to verify Optimized performance of IGSA.

The value of the optimal model parameters $\left(\mathrm{C}, \sigma^{2}\right)$ obtained by IGSA is $(655,184)$. This group of parameters is used to predict the regression data of 1 and 2 sets of prediction data and another 17 sets of training data, and simultaneously with the other three methods. The model is compared experimentally, and the prediction error is shown in Figure 2 below. Table 3 shows the relative error (RE) of the four prediction methods for predicting NOx emissions.

Table 3. Precision analysis of forecast results of 4 algorithms for testing set

\begin{tabular}{cccccccc}
\hline working & NOx value & GSA & RE $(\%)$ & IGSA & RE(\%) & IGSA-War & RE(\%) \\
\hline 1 & 585.9 & 596.0512 & 1.7326 & 581.1867 & 0.8045 & 589.0208 & 0.5326 \\
2 & 906.15 & 911.5982 & 0.6012 & 901.9478 & 0.4637 & 908.0396 & 0.2085 \\
\hline
\end{tabular}


From Figure 3 and Table 3, we can see that the IGSA optimizes the wavelet model parameters, and then the prediction accuracy based on the optimized parameters is higher than that of the GSA, IGSA, and IGSA-War optimization models. That is, IGSAWar can compare with GSA, IGSA, IGSA-War finds better model parameters.

\section{Comparison of models considering the existence of noise}

Random noise is added to the ecological emissions in Figure 1 to test the robustness. The noise emission prediction results and prediction errors of IGSA-War are shown in Figures 3 and 4.

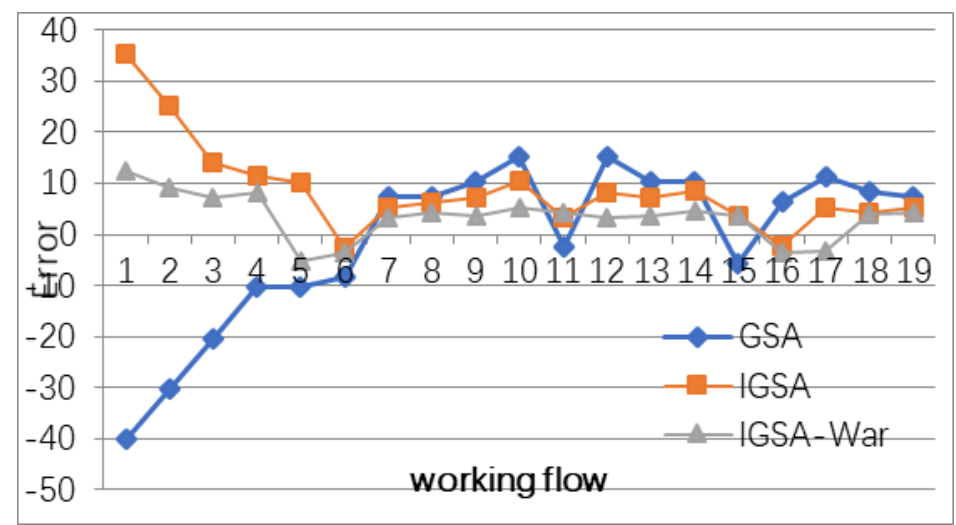

Figure 2. Error curve between prediction value s and true values of 4 algorithms

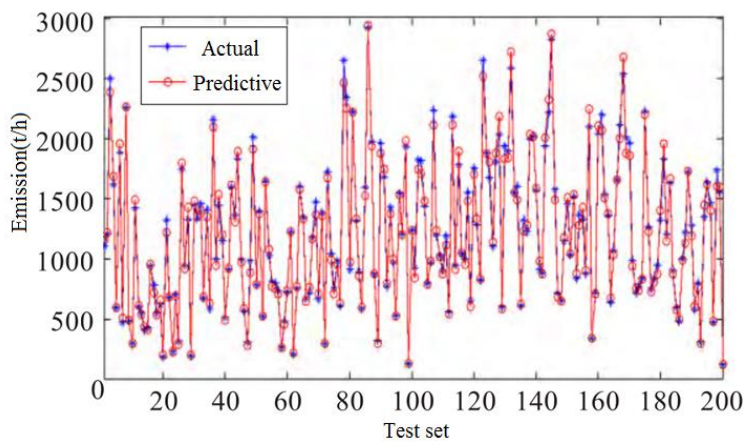

Figure 3. Prediction in the test data set

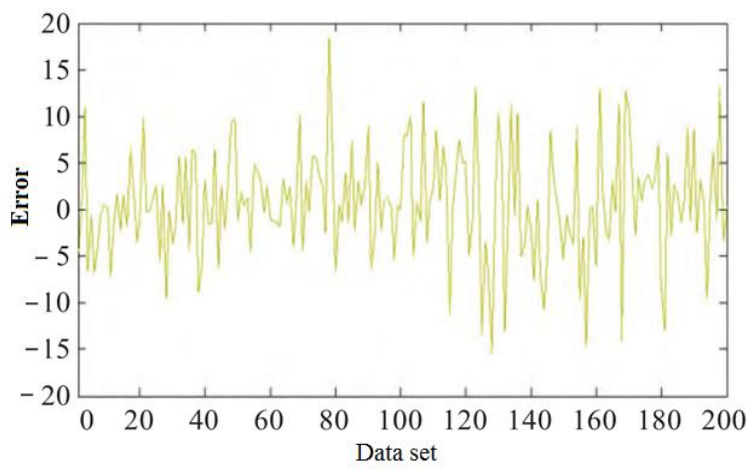

Figure 4. Error in the test data set 
For noise emission prediction (Fig. 3), IGSA-War also obtains an ideal prediction effect, and the prediction error is controlled within an effective range (Khanchoul and Boubehziz, 2019). This is because IGSA-War comprehensively weighs the principle of structural risk minimization and empirical risk minimization, so that the model has certain Anti-noise ability, can adapt to the characteristics of complex and variable, noisy ecological environment changes. The data set is used as the test set, and the other data is used as the training set. The experimental results once again prove the effectiveness of IGSA-War for ecological emission prediction (Fig. 4).

\section{Conclusion}

The characteristics of NOx emissions from ecological emissions are affected by many factors, and the impact relationship is complicated. The prediction and control of NOx emissions are difficult. This paper uses IGSA-War to establish a NOx emission prediction model. In order to improve the prediction accuracy and generalization ability of IGSA, an improved gravitational search algorithm is used to optimize the model parameters of wavelet selection. Taking a $330 \mathrm{MW}$ pulverized coal fired boiler as a test object, the IGSA algorithm is used to optimize the super-parameters of the wavelet and establish a prediction model of NOx emissions. By using the relevant data collected by the DCS as training samples and test samples, the model is trained and tested. Experiments show that the IGSA-optimized wavelet NOx emission prediction model has better accuracy and stronger generalization ability.

Acknowledgements. This work supported by Chongqing Municipal Education Commission Science and Technology Project (KJQN201802101); Doctoral high school talent training project (RC2016003); Chongqing Graduate Scientific Research Innovation Project (CYB17131); Nature Science Research Programme of the Education Department of Fujian Province (No.JAT160410).

\section{REFERENCES}

[1] Azeem, N., Arslan, C. H., Rashid, H., Sattar, A. (2018): Comparative Study Of Hospital Waste Management Practices At Different Health Care Units In District Faisalabad For The Development Of Improvement Strategies. - Earth Sciences Pakistan 2(2): 16-21.

[2] Chen, C., Song, H., Yang, H. (2017): Liouville type theorems for stable solutions of pLaplace equation in RN. - Nonlinear Analysis 160: 44-52.

[3] Dager, M. R. (2017): Composición de la materia orgánica, $\mathrm{pH}$, intercambio catiónico y textura de cinco suelos ubicados entre 670 y $1600 \mathrm{msnm}$ en la cuenca del río Maracay, Venezuela. - Revista de la Facultad de Agronomia de la Universidad del Zulia 34(2): 5360.

[4] Espinoza, Y. (2017): Efecto del sistema labranza sobre la estructura y fracciones de carbono y nitrógeno del suelo y su impacto en el desarrollo del cultivo de maíz. - Revista de la Facultad de Agronomia de la Universidad del Zulia 34(4): 94-100.

[5] Franco, G. H., Macancela, N. A., Gavín-Quinchuela, T., Carrión-Mero, P. (2018): Participatory socio-ecological system: Manglaralto-Santa Elena, Ecuador. - Geology, Ecology, and Landscapes 2(4): 303-310.

[6] Gouthamkumar, N., Sharma, V., Naresh, R. (2015): Disruption based gravitational search algorithm for short term hydrothermal scheduling. - Expert Systems with Applications 42(20): 7000-7011. 
[7] Hossain, M. S., Karlson, M., Neset, T. S. (2019): Application Of Gis For Cyclone Vulnerability Analysis Of Bangladesh. - Earth Sciences Malaysia 3(1): 25-34.

[8] Jaimes, E. J. (2017): Capacidad de carga y presión de uso de la tierra en cuatro sectores de la sub-cuenca del río Déleg, Provincia del Cañar, Ecuador. - Revista de la Facultad de Agronomia de la Universidad del Zulia 34(3): 75-81.

[9] Kang, L., Zhang, Y. J., Zhang, L., Zhang, K. (2017): Preparation, characterization and photocatalytic activity of novel $\mathrm{CeO} 2$ loaded porous alkali-activated steel slag-based binding material. - International Journal of Hydrogen Energy 42(27): 17341-17349.

[10] Kang, L., Du, H. L., Du, X., Wang, H. T., Ma, W. L., Wang, M. L., Zhang, F. B. (2018): Study on dye wastewater treatment of tunable conductivity solid-waste-based composite cementitious material catalyst. - Desalination and Water Treatment 125: 296-301.

[11] Khanchoul, K., Saaidia, B., Altschul, R. (2018): Variation in Sediment Concentration and Water Disharge During Storm Events in Two Catchments, Northeast of Algeria. - Earth Sciences Malaysia 2(2): 01-09.

[12] Khanchoul, K., Boubehziz, S. (2019): Spatial Variability Of Soil Erodibility At El Hammam Catchment, Northeast Of Algeria. - Environment \& Ecosystem Science 3(1): 17-25.

[13] Kumar, R. (2018): Comparison Of Instruction Scheduling And Register Allocation For Mips And Hpl -Pd Architecture For Exploitation Of Instruction Level Parallelism. Engineering Heritage Journal 2(2): 04-08.

[14] Li, G. Q., Niu, P. F., Zhang, W. P. (2003): Model NOx emissions by least squares support vector machine with tuning based on ameliorated teaching-learning-based optimization. Chemometrics and Intelligent Laboratory Systems 126: 11-20.

[15] Li, X. Y., Zhao, Q. L. (2017): A new integrable symplectic map by the binary nonlinearization to the super AKNS system. - Journal of Geometry and Physics 121: 123137.

[16] Liu, C., Niu, P. F. (2015): Enhanced shuffled frog-leaping algorithm for solving numerical function optimization problems. - Journal of Intelligent Manufacturing 29(5): 1133-1153.

[17] Liu, P. F., Liu, C., Li, G. Q. (2015): Investigation on Multi-model Modeling Method of Steam Turbine Heat Rate. - Acta Metrologica Sinica 36(3): 251-255.

[18] López-Hernández, D. (2018): Áreas superficiales específicas y parámetros asociados en suelos venezolanos con diferentes grados de pedogénesis. - Revista de la Facultad de Agronomia de la Universidad del Zulia 35(3): 111-116.

[19] Lv, Y., Feng, H., Ting, T. (2017): A dynamic model for the bed temperature prediction of circulating fluidized bed boilers based on least squares support vector machine with real operational data. - Energy 124(4): 284-294.

[20] Niu, P. F., Wang, P. K., Li, G. Q. (2014): Modeling and Optimization of NOx for Coalfired Boilers by Free Search Algorithm and Support Vector Machine. - Acta Metrologica Sinica 35(6): 626-630.

[21] Niu, P. F., Ma, Y. P., Zhang, J. (2016): Utility Boilers NOx Combustion Optimization Based on Relevance Vector Machine. - Acta Metrologica Sinica 37(2): 191-196.

[22] Nouaim, W., Chakiri, S., Rambourg, D., Karaoui, I., Ettaqy, A., Chao, J., Allouza, M., Razoki, B., Yazidi, M., Hmidi, F. E. (2019): Mapping the water erosion risk in the Lakhdar river basin (central High Atlas, Morocco). - Geology, Ecology, and Landscapes 3(1): 22-28.

[23] Olivares, B., Cortez, A., Lobo, D., Parra, R., Rey, J., Rodríguez, M. (2017): Evaluación de la vulnerabilidad agrícola a la sequía meteorológica en diferentes localidades de Venezuela. - Revista de la Facultad de Agronomía 34(1): 103-129.

[24] Pang, Z. H., Liu, G. P., Zhou, D., Sun, D. (2016): Data-based predictive control for networked nonlinear systems with network-induced delay and packet dropout. - IEEE Transactions on Industrial Electronics 63(2): 1249-1257. 
[25] Pascual-Córdova, G. (2018): Indicadores de calidad del suelo en el agroecosistema caña de azúcar (Saccharum spp.). - Revista de la Facultad de Agronomia de la Universidad del Zulia 35(1): 98-104.

[26] Rajput, K., Gupta, A., Hi, A. (2019): Re-Cycle Of E-Waste In Concrete By Partial Replacement Of Coarse Aggregate. - Engineering Heritage Journal 1(1): 05-08.

[27] Rashedi, E., Nezanudmdi-pour, H., Saryazdi, S. (2009): GSA: A Gravitational Search Algorithm. - Information Sciences 179(13): 2232-2248.

[28] Sharjeel, A., Anwar, S., Nasir, A., Rashid, H. (2019): Design, Development And Performance Of Optimum Water Softener. - Earth Sciences Pakistan 3(1): 23-28.

[29] Tan, P., Xia, J. (2014): Modeling and optimization of NOX emission in a coal-fired power plant using advanced machine learning methods. - Energy Procedia 61:377-380.

[30] Yazdani, S., Nezanudmdi-pour, H., Kamyab, H. (2014): A gravitational search algorithm for multimodal optimization. - Swarm and Evolutionary Computation 14: 1-14.

[31] Zhang, W. P., Zhao, W. L., Niu, P. F. (2015): Forecasting of Turbine Main Steam Flow Based on Rough Sets and Least Squars Support Vector Machine Regression. - Acta Metrologica Sinica 36(1): 43-47.

[32] Zhang, W., Ma, L., Zhang, T. (2017): Discrete-time mean-field stochastic H 2/Hळ control. - Journal of Systems Science and Complexity 30(4): 765-781.

[33] Zhang, L., Khalique, C. (2018): Classification and bifurcation of a class of second-order odes and its application to nonlinear PDES. - Discrete \& Continuous Dynamical Systems-Series S 11(4).

[34] Zulkapli, M. F., Rashid, N. M., Sokri, M. N. M., Nasri, N. (2018): Study On Optical Properties Of Graphene-Tio2 Nanocomposite As Photoanodes Layer In Dye Sensitized Solar Cell (Dssc). - Environment \& Ecosystem Science 2(2): 39-41. 